\title{
GAME PENGENALAN ORGAN TUBUH MANUSIA BERBASIS MULTIMEDIA MENGGUNAKAN STRUKTUR ALUR MULTIMEDIA HIERARKI
}

\author{
Hamdan $^{1 *}$, Umar Mansyuri ${ }^{2}$, Beni Junedi ${ }^{3}$ \\ 1,2,3 Universitas Bina Bangsa \\ *Hamdan0419087701@gmail.com
}

\begin{abstract}
ABSTRAK
Ilmu pengetahuan alam merupakan ilmu yang mempelajari tentang alam dan segala isinya yang ada didalamnya, salah satunya mempelajari tentang organ tubuh manusia yang terbagi dua bagian yaitu organ dalam dan organ luar manusia. Penyampaian materi pembelajaran di sekolah masih bersifat konvensional yaitu menggunakan media buku cetak. Media penyampaian yang masih konvensional dan banyak istilah-istilah pada materi organ manusia menyebabkan siswa-siswi kesulitan dalam memahami materi. Banyak media yang bisa diterapkan dalam pembelajaran organ tubuh manusia, salah satunya dengan menggunakan media game pembelajaran. Game adalah media penyampaian yang banyak dinikmati oleh semua kalangan. Sehingga perlu membuat suatu sistem aplikasi atau game pembelajaran berbasis multimedia, sebagai solusi pemecahan masalah kesulitan siswa memahami materi. Multimedia memiliki aspekaspek yang diminati kalangan siswa karena tampilannya berupa gambar, animasi, audio, dan video. Pada perancangan game organ tubuh manusia ini menggunakan struktur alur multimedia hirarki, adapun software yang digunakan untuk membangun game ini ialah adobe photoshop, Adobe Flash, dan coreldraw. Hasil dari perancangan game tersebut akan diimplementasikan menjadi sebuah game pengenalan organ tubuh manusia berbasis multimedia menggunakan sruktur hierarki multimedia yang diharapkan mampu menjadi salah satu cara penyampaian materi yang efektif dalam mengatasi berbagai masalah yang terjadi dalam pembelajaran organ tubuh manusia.
\end{abstract}

Kata kunci: game, struktur alur hierarki multimedia, materi organ tubuh manusia

\begin{abstract}
Natural science is the study of nature and all its contents in it, one of which studies the human body organs which are divided into two parts, namely internal organs and human external organs. The delivery of learning materials in schools is still conventional, namely using the media of printed books. The delivery media that is still conventional and many terms on the material of human organs cause students to have difficulty in understanding the material. There are many media that can be applied in learning human organs, one of which is by using learning game media. Game is a medium of delivery that is widely enjoyed by all people. So it is necessary to create an application system or multimedia-based learning game, as a solution to solving the problem of students' difficulties in understanding the material. Multimedia has aspects that are of interest to students because of its appearance in the form of images, animations, audio, and video. In designing this game, the human body uses a hierarchical multimedia flow structure, while the software used to build this game is Adobe Photoshop, Adobe Flash, and CorelDraw. The results of the game design will be implemented into a multimedia-based human organ recognition game using a multimedia hierarchy structure which is expected to be an effective way of delivering material in overcoming various problems that occur in learning human organs.
\end{abstract}

Keywords: Game, multimedia hierarchical flow structure, human organ material. 
Prosiding The 1st National Conference on Applied Business, Education, \& Technology (NCABET)"

Unversitas Bina Bangsa 2021

DOI Article : 10.46306/ncabet.v1i1.45

\section{PENDAHULUAN}

Ilmu Pengetahuan alam adalah ilmu yang mempelajari tentang alam dan segala isi yang ada didalamnya. Manusia adalah salah satu yang termasuk dalam bagian dari alam, dalam ilmu pengetahuan alam di pelajarilah tentang manusia beserta pengenalan organ tubuh manusia. materi pembelajaran tentang organ tubuh manusia kurang mampu diterima oleh siswa dan disampaikan dengan baik, "Karena masih bersifat konvensional atau hanya menggunakan buku teks saja, sehingga tidak ada animasi maupun simulasi yang dapat membantu para siswa memahami materi" (Ridwan dan Christianto, 2011). media penyampaian untuk menyampaikan materi tentang organ tubuh manusia tentu harus dibuat lebih baik dan lebih menarik di bandingkan dengan media yang menitikberatkan pada buku pelajaran. Salah satunya dengan menggunakan game interaktif multimedia.

Menurut setiani (2013) "Citra game di masyarakat masih dipandang sebagai media yang menghibur dibanding sebagai media pembelajaran. Sifat dasar game yang menantang, membuat ketagihan dan menyenangkan bagi mereka yang menyukai permainan modern ini dapat berdampak negatif apabila yang dimainkan adalah game yang tidak bersifat edukasional. Untuk itu perlu dikembangkan sebuah game edukasi yang dapat digunakan sebagai media pembelajaran yang dapat memotivasi siswa agar tertarik dalam belajar" (Setiani, 2013).

Game organ tubuh manusia ini akan membuat siswa lebih mudah mengingat materi dan menghafal apa yang telah di pelajari tentang organ tubuh manusia di sekolah. Dalam game organ ini siswa akan bermain dengan cara memilih jawaban yang tepat dari soal yang muncul pada setiap level nya dan pada setiap level tersebut memiliki tingkat kesulitan masing-masing karna hal tersebut secara tidak langsung siswa akan mempelajari ulang materi tentang organ tubuh manusia dan mengingat kembali bagian-bagian dari organ tubuh manusia dan fungsinya serta nama dari bagian organ tersebut. Beberapa game yang pernah dirancang adalah game edukasi untuk pembelajaran matematika, game edukasi meningkatkan daya ingat anak "bermain bersama dido", dan aplikasi game edukasi untuk pengajaran bahasa inggris pada anak-anak. (Ciputra, 2013; Suindarti, 2011; khairunisa, 2010)

Penulisan ini bertujuan untuk menghasilkan game pembelajaran yang mampu menunjang materi pembelajaran tentang Organ tubuh manusia dan mampu meningkatkan mutu pendidikan bagi siswa sekolah menengah atas dan sederajat dan mampu mengembangkan penelitian ini sehingga bisa bermanfaat bagi siswa sekolah menengah atas dan sederajat.

\section{METODE PENELITIAN}

Penelitian ini di paparkan dalam Story Board/alur diagram multimedia, perancangan antarmuka seperti yang tertera dibawah ini: 


\section{Story Board/ Alur Diagram Multimedia}

Perancangan naskah pada multimedia memberikan gambaran umum mengenai subjek game pembelajaran multimedia, agar lebih bisa digunakan oleh pemakai maka diperlukan rancangan yang terurut dan terperinci. Adapun gambaran serta keterangan kegiatan menulis naskah dapat dilihat pada diagram hierarki berikut:

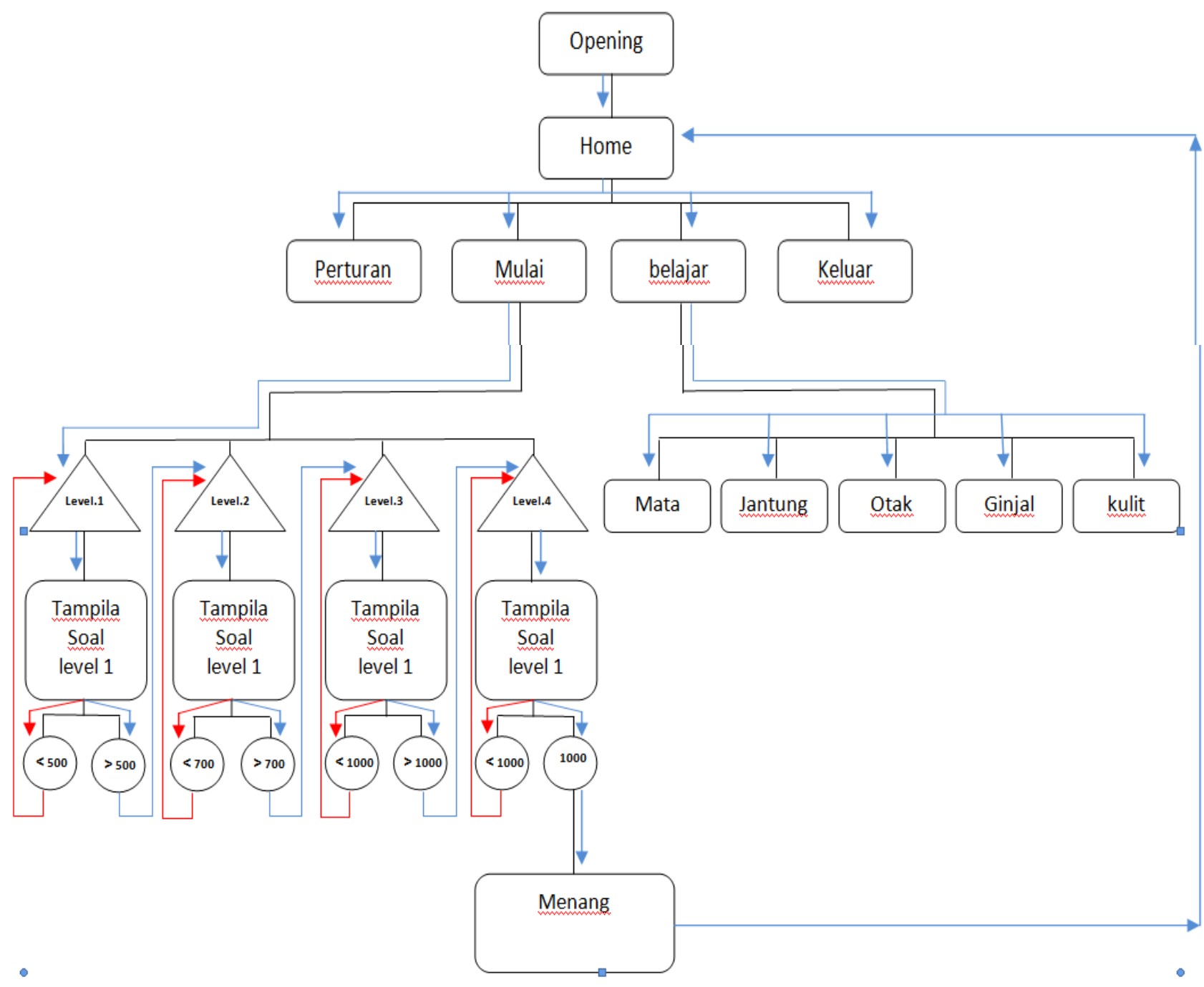

Gambar 1. Diagram Struktur Hierarki Game Organ Tubuh Manusia

\section{Perancangan antar muka}

Tujuan dari perancangan antarmuka situs adalah untuk membuat antarmuka yang user-friendly. Ciri dari sebuah aplikasi yang user-friendly adalah tampilan bagus, mudah digunakan, mudah dipelajari, dan menyenangkan (tidak membosankan).

a. Tampilan opening 
Prosiding The 1st National Conference on Applied Business, Education, \& Technology (NCABET)”,

Unversitas Bina Bangsa 2021

DOI Article : 10.46306/ncabet.v1i1.45

Tampilan opening pada game ini adalah tampilan yang berisikan animasi pembuat dan email pembuat game, pada tampilan ini mempergunakan background degradasi abu-abu dan bermotif gambar-gambar organ tubuh manusia.

b. Tampilan Menu Utama

Tampilan menu utama pada game ini adalah tampilan yang berisikan animasi gerak tombol tombol dan berisikan empat tombol untuk memulai permainan, melihat peraturan game organ tubuh manusia dan keluar dari game organ tubuh manusia, pada tampilan ini mempergunakan background degradasi abu-abu dan bermotif gambar-gambar organ tubuh manusia.

c. Tampilan level 1 s.d 4

Tampilan level pada game ini adalah tampilan yang berisikan animasi gerak tombol tombol dan teks level dan animasi line. Tampilan level juga berisikan enam tombol untuk memulai level satu, level dua, level tiga dan level empat, namun hanya dapat memulai dari level satu dan seterusnya. pada tampilan ini mempergunakan background degradasi abu-abu dan bermotif gambar-gambar organ tubuh manusia.

\section{d. Tampilan salah}

Tampilan salah pada game ini adalah tampilan yang berisikan teks penjelasan dan serta tombol, yang menjelaskan bahwa pemain memberikan jawaban yang salah. Tampilan salah memiliki 3 tombol, tombol next untuk menuju soal berikutnya, tombol home untuk kembali ketampilan menu awal dan tombol close untuk keluar dari permainan. pada tampilan ini mempergunakan background bewarna abu-abu.

\section{e. Tampilan benar}

Tampilan benar pada game ini adalah tampilan yang berisikan teks penjelasan dan serta tombol, yang menjelaskan bahwa pemain memberikan jawaban yang benar. Tampilan benar memiliki 3 tombol, tombol next untuk menuju soal berikutnya, tombol home untuk kembali ketampilan menu awal dan tombol close untuk keluar dari permainan. pada tampilan ini mempergunakan background bewarna abu-abu.

\section{f. Tampilan Soal level 1 s.d 4}

Tampilan Soal level 1 pada game ini adalah tampilan yang berisikan teks soal, gambar soal, animasi, tombol-tombol jawaban. Tampilan Soal level 1 berisikan tujuh tombol yang satu tombol berfungsi untuk lanjut ke tampilan benar, dan empat tombol lain nya menampilkan tampilan salah dan tombol home untuk kembali ketampilan menu awal dan tombol close untuk keluar dari permainan. pada tampilan ini mempergunakan background degradasi abu-abu dan bermotif gambargambar organ tubuh manusia.

g. Tampilan Tamat 
Tampilan tamat pada game ini adalah tampilan yang berisikan teks, gambar, tombol kembali ke home yang berupa gambar organ manusia. Tampilan tamat mamiliki satu tombol yaitu tombol yang berfungsi untuk kembali ke tampilan menu utama. Tampilan ini akan muncul jika pemain mampu menyelesaikan pertanyaan sampai akhir.

h. Tampilan belajar

Tampilan belajar pada game ini adalah tampilan yang berisikan teks, gambar, tombol. Tampilan belajar mamiliki tujuh tombol yaitu tombol yang berfungsi untuk menampilkan isi pembelajaran.

i. Tampilan Peraturan

Tampilan Peraturan pada game ini adalah tampilan yang berisikan animasi teks dan beberapa tombol yang berfungsi untuk menampilkan penjelasan dari setiap level pada game ini. Tampilan peraturan menggunakan background abu-abu bermotif organ organ tubuh manusia.

j. Tampilan Input Nama Pemain.

Tampilan input nama pemain pada game ini adalah tampilan yang berisikan kolom teks dan satu tombol yang berfungsi untuk lanjut ketampilan soal dari setiap level pada game ini. Tampilan peraturan menggunakan background abu-abu bermotif organ organ tubuh

k. Tampilan Hasil Akhir.

Tampilan hasil akhir pada game ini adalah tampilan yang berisikan teks nama pemain, jumlah soal yang benar, jumlah soal yang salah, skor yang dihasilkan dan empat buah tombol. Tampilan hasil akhir menggunakan background abu-abu bermotif organ organ tubuh manusia.

Teknik pengumpulan data pada penelitian ini menggunakan kuesioner dengan skala Gutman. Data dianalisis dengan menggunakan statistika deskripitif. Hasil akhir dari penelitian beruapa produk game berbasis multimedia. Pada pembuatan game pembelajaran ini, akan menggunakan berbagai macam software. yaitu: Corel draw, Adobe Flash, Adobe Photoshop dan sistem operasi yang digunakan adalah windows 10. Kebutuhan Perangkat Keras Dalam pengerjaan tugas akhir ini adalah menggunakan laptop.

\section{HASIL DAN PEMBAHASAN}

Hasil akhir dari pembuatan program aplikasi game pembelajaran berbasis multimedia ini dapat disajikan dalam bentuk CD interaktif yang dapat dihgunakan oleh masyarakat yang membutuhkan. Selain itu hasilnya dapat disimpan kedalam flashdisk dan CDROM, juga dapat dikonversi ke dalam website untuk dapat diakses dengan mudah. 
Prosiding The 1st National Conference on Applied Business, Education, \& Technology (NCABET)",

Unversitas Bina Bangsa 2021

DOI Article : 10.46306/ncabet.v1i1.45

Hasil atau output tampilan dari rancangan program pembuatan game organ tubuh manusia, yaitu berupa form-form tampilan dan penjelasan mengenai proses terjadinya tampilan tersebut, adalah sebagai berikut:

\section{Form Opening \& Menu Utama}

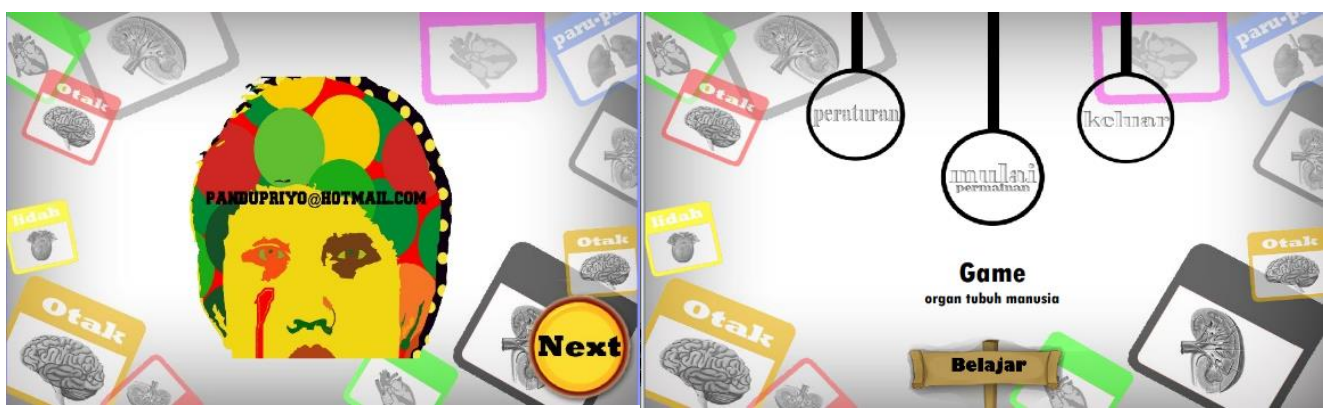

Gambar 2. Form Opening

Ini adalah tampilan awal sebagai pembuka yang menyuguhkan beberapa animasi tulisan pada Game Organ Tubuh Manusia berupa alamat email pembuat dan tombol menuju tampilan home.

Form menu utama merupakan awal dari permainan yang akan di mulai. Dalam tampilan menu utama terdapat beberapa tombol seperti: peraturan yang berfungsi untuk menampilkan peraturan dari game organ tubuh manusia, mulai permainan yang berfungsi untuk memulai permainan, tombol belajar yang berfungsi untuk memulai pembelajaran dan Tombol keluar untuk keluar dari aplikasi.

\section{Form Peraturan \& Input nama}

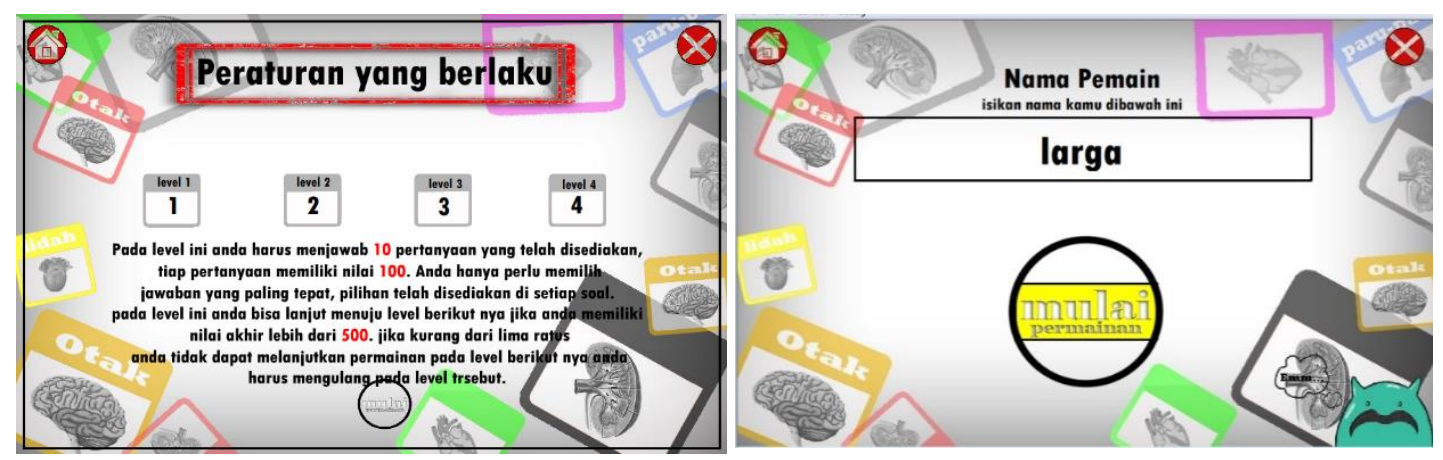

Gambar 3. Form Peraturan

Form peraturan merupakan tempat menampilkan peraturan-peraturan yang berlaku pada game organ tubuh manusia. Pada tampilan ini terdapat teks penjelasan peraturan setiap level serta tiga tombol yaitu tombol home, tombol close, dan tombol mulai permainan. Form ini berfungsi untuk menginput nama pemain yang akan ditampilkan pada form selanjutnya. Pada form ini terdapat tiga buah tombol yaitu tombol home, tombol close dan tombol ok yang berfingsi untuk lanjut ke tampilan soal.

\section{Form Level $1 \&$ soal level 1 s.d 4}




\section{Gambar 4. Form level 1}

Form level 1 terdapat 6 tombol untuk menuju tiap level, tombol home dan tombol keluar. Namun pada tampilan level 1 tombol level yang berfungsi hanya satu tombol, karna pemain belum memenangkan level- level lainnya. Level ini berada pada awal permainan. Form ini berisi soal yang harus dijawab oleh sipemain. Didalam form ini terdapat nama pemain, no urut soal, nilai pemain, gambar soal, animasi tombol jawaban, soal, tombol home, tombol close, dan lima tombol jawaban.

\section{Form Tampilan Benar \& Salah}
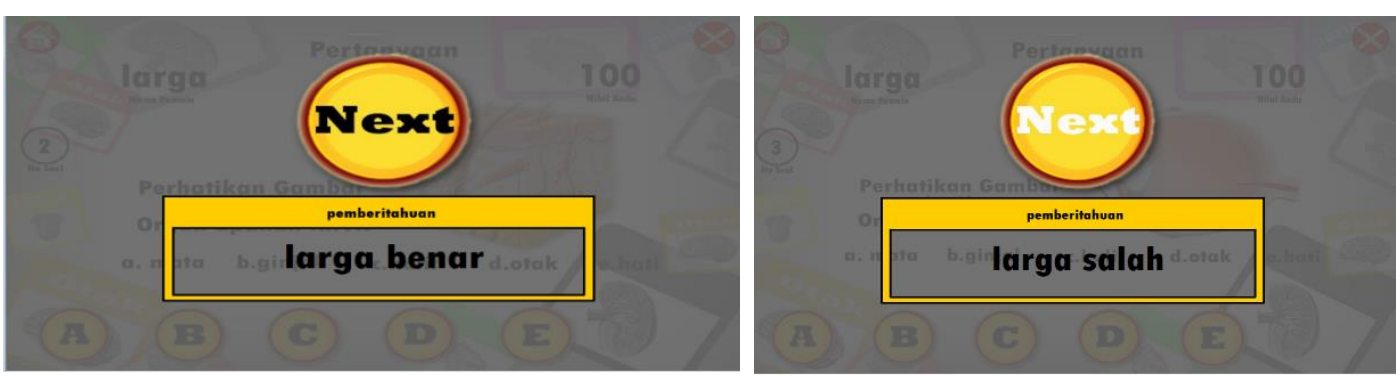

Gambar 5. Form tampilan benar dan salah

Form ini berisi pemberitahuan jawaban yang dipilih pemain benar dan terdapat satu buah tombol untuk melanjut kesoal berikutnya. Form ini berisi pemberitahuan jawaban yang dipilih pemain benar dan terdapat satu buah tombol untuk melanjut kesoal berikutnya.

\section{Form Hasil Akhir Level 1 s.d 4 \& Tamat}

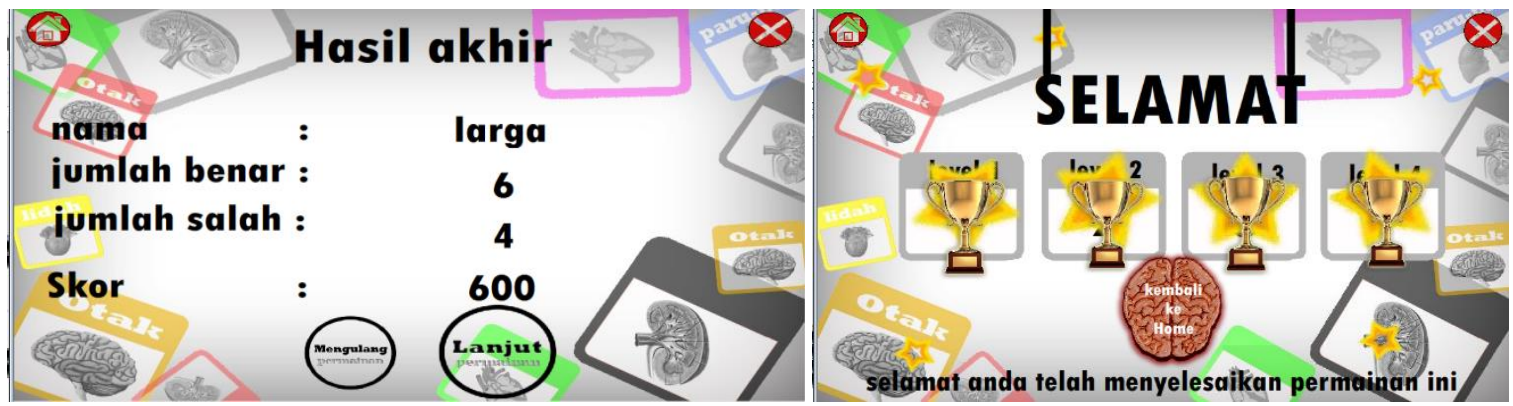

Gambar 6. Form hasil akhir level 1

Form ini menjelaskan hasil akhri yang didapatkan pemain pada level 1. Dalam form ini terdapat nama pemain, jumblah soal yg dijawab benar, jumlah soal yang dijawab salah, skor pemain, tombol mengulang berfungsi untuk mengulang soal, tombol lanjut berfungsi untuk melanjutkan soal ke level dua jika nilai skor yang didapatkan lebih dari 500, tombol home, dan tombol close. 
Prosiding The 1st National Conference on Applied Business, Education, \& Technology (NCABET)”,

Unversitas Bina Bangsa 2021

DOI Article : 10.46306/ncabet.v1i1.45

Form ini adalam tampilan yang paling akhir pada game ini, pada tampilan ini terdapat animasi gambar, dan animasi teks. Tampilan ini menginformasikan bahwa pemain telah menyelesaykan semua level pada game, telah mengumpulkan semua bintang pada setiap level. Tampilan ini memiliki satu tombol yang berfungsi sebagai tombol nafigasi untuk kembali pada tampilan menu utama.

\section{Form pembelajaran}

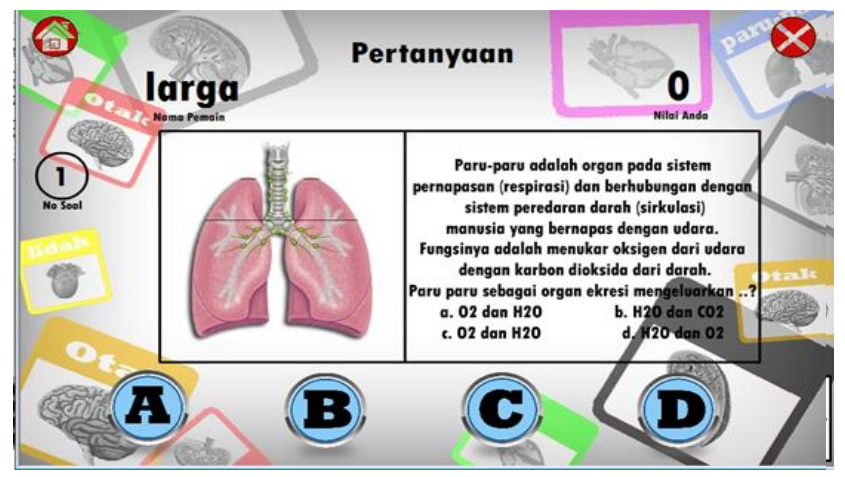

Gambar 7. Form pembelajaran

Form pembelajaran ini tentang sekilas materi tentang beberapa organ yang akan dibahas pada game seperti mata, kulit, otak, jantung, ginjal.

Pengujian sistem yang diterapkan pada penelitian ini adalah dengan menggunakan metode alfa yang terdiri dari 5 koresponden dan dalam kuissioner terdapat 12 pertanyaan. Hasil yang di dapatkan dari 5 koresponden dapat di lihat dari gambar grafik dibawah ini.

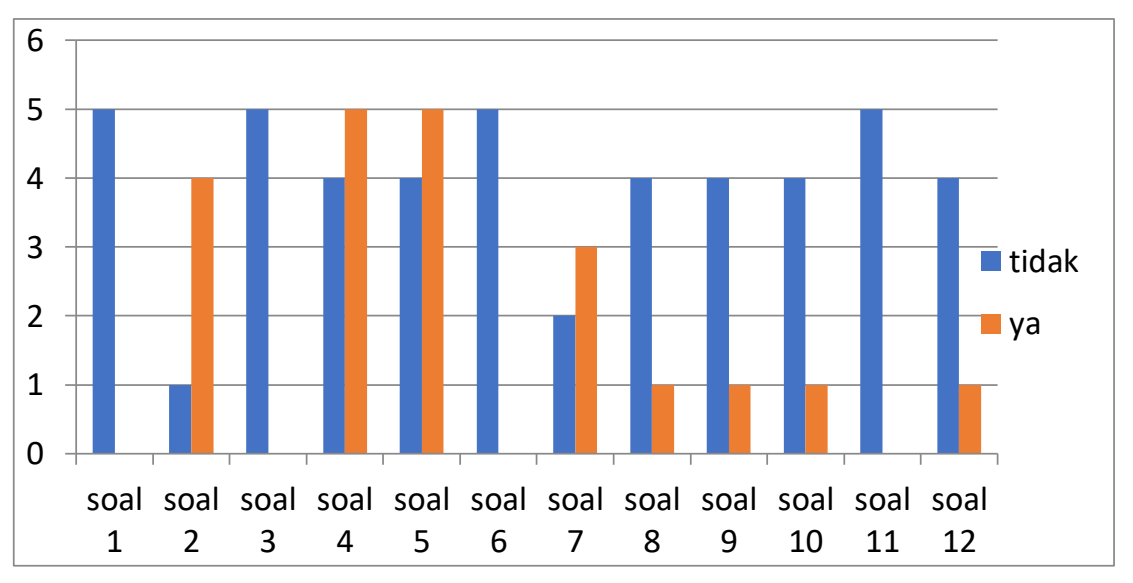

Gambar 8. Grafik penilaian game organ tubuh manusia

Setelah dilakukan pengetesan game multimedia ini dapat digunakan oleh siapa saja yang ingin belajar organ tubuh manusia tanpa membatasi hak aksesnya. Baik untuk belajar sendiri maupun digunakan untuk pengajar. Karena user dapat menggunakan game ini sebagai media pembelajaran. Proses penggunaannya membutuhkan bantuan mouse sebagai alat masukan (input) dan monitor sebagai alat keluaran (output) untuk menampilkan design, serta speaker untuk menampilkan suara.

Aplikasi sistem multimedia yang sudah bisa digunakan dapat disimpan atau dipelihara dengan baik tanpa harus diupdate secara rutin seperti game multimedia, karena game organ tubuh manusia ini sudah merupakan materi yang pasti dan tidak dapat dirubah secara signifikan. Kecuali perubahan 
dalam pengeditan design warna, gambar, animasi, suara, narasi, serta hal-hal lain yang berhubungan dengan komponen-komponen mulltimedia saja.

\section{KESIMPULAN DAN SARAN}

Kesimpulan dalam penelitian ini yaitu dengan aplikasi game pembelajaran organ tubuh manusia berbasis multimedia mampu menjelaskan, meningkatkan motivasi setiap siswa-siswi dalam belajar. Dengan menerapkan struktur alur multimedia hierarki game organ tubuh manusia mampu dibuat lebih mudah, karena struktur alur multimedia hierarki mempermudah dalam membuat sistem serta alur dalam game tersebut. Beberapa saran yang harus diperhatikan yaitu perlu pengembangan aplikasi lebih baik lagi agar dapat dimanfaatkan dengan baik oleh semua instansi pendidikan yang mempelajari organ tubuh manusia. Dilakukan penelitian dan pengkajian ulang secara signifikan agar mendapatkan hasil yang lebih baik serta solusi yang tepat untuk meningkatkan mutu pendidikan khususnya dalam mempelajari mata pelajaran Biologi dalam materi organ tubuh manusia.

\section{UCAPAN TERIMAKASIH}

Penulis mengucapkan terimakasih kepada Lembaga Penelitian dan Pengabdian Kepada Masyarakat (LPPM) yang telah memfasilitasi penelitian ini sehingga berjalan dengan lancar dan baik. Penelitian ini terlaksana dengan baik berkat semangat dan dukungan tim, sehingga penelitian berjalan dengan sesuai dengan jadwal dan target yang telah ditetapkan.

\section{DAFTAR PUSTAKA}

Ahdan, S., Putri, A. R., \& Sucipto, A. (2020). Aplikasi M-Learning sebagai Media Pembelajaran Conversation pada Homey English. SISTEMASI: Jurnal Sistem Informasi, 9(3), 493-509.

Daryanto. (2015). Media Pembelajaran. Bandung: Pt. Sarana Tutorial Nurani Sejahtera.

Dewi Keumalasari. 2016, Kumpulan Bank soal Paling Update Cerdas Biologi Kelas X, XI, XII, Grasindo

Eisner, E.W. 1970. Media, expression, and the arts, Dalam G. Salomoh \& R.E Snow (Eds), Commentaries on Research in Instructional Media, Bloomington, Indiana University.

Jogiyanto, Hm. 2001. Analisis Perancangan Sistem Informasi. Andi Offset. Yogyakarta.

Rozinah Jamaludin,2005, Multimedia dalam Pendidikan, Educational Technology, Taman Shamelin Perkasa. 